\title{
O sofrimento psíquico na sociedade capitalista e neoliberal sob a ótica da determinação social do processo saúde-doença
}

\section{Psychic suffering in capitalist and neoliberal society from the perspective of social determination of the health-disease process}

\section{Giovanna Innocencio}

Como citar esse artigo. INNOCENCIO,

G. O sofrimento psíquico na sociedade capitalista e neoliberal sob a ótica da determinação social do processo saúde-doença. Mosaico - Revista Multidisciplinar de Humanidades, Vassouras, v. 12, n. 3, p. 16-22, set./ dez. 2021.

\section{Resumo}

O presente artigo tem como objetivo sistematizar, através de uma revisão narrativa da literatura, as diferentes teorias que surgiram na tentativa de explicação do processo saúde-doença, e tomar como base os determinantes sociais da saúde, cujo referencial teórico reconhece a existência de um nexo biopsíquico constituidor dos indivíduos e estabelecido em sociedade, para analisar a epidemiologia do sofrimento psíquico na sociedade contemporânea. Será destacado como o processo de exploração advindo do modo de produção capitalista e neoliberal, correlacionando com as diferenças sociais de classe, gênero e raça, tem tamanha responsabilidade na alta prevalência dos transtornos mentais na sociedade. Mostra-se, dessa forma, como é inegável conceber a dialética entre as ciências médicas e ciências humanas para o adequado desenvolvimento da saúde mental.

Palavras-chave: sofrimento psíquico; determinantes sociais da saúde; transtornos mentais; capitalismo.

Nota da Editora. Os artigos publicados na Revista Mosaico são de responsabilidade de seus autores. As informações neles contidas, bem como as opiniões emitidas, não representam pontos de vista da Universidade de Vassouras ou de suas Revistas.

\begin{abstract}
This article aims to systematize, through a narrative review of literature, the different theories that emerged in an attempt to explain the health-disease process, and to take as a basis the social determinants of health, whose theoretical framework recognizes the existence of a biopsychic nexus constituting individuals and established in society, to analyze the epidemiology of psychological suffering in contemporary society. It will be highlighted how the process of exploitation arising from the capitalist and neoliberal mode of production, correlating with the social differences of class, gender and race, has such a responsibility in the high prevalence of mental disorders in society. In this way, it is shown how undeniable it is to conceive the dialectic between the medical sciences and the human sciences for the adequate development of mental health.

Keywords: psychological distress; social determinants of health; mental disorders; capitalism.
\end{abstract}

\section{Introdução}

Ao longo da história, diversas teorias explicativas surgiram na tentativa de construir significados sobre a relação da estrutura e das funções do corpo com o meio ambiente, o que possibilitou a eclosão de diferentes narrativas do processo saúde-doença. Nesse sentido, numerosos projetos de intervenção foram criados de acordo com as necessidades coletivas de cada sociedade.

A fim de compreender as formas particulares de sofrimento psíquico na sociedade contemporânea, este estudo tomou a teoria da determinação social como base para tal análise. Para Breilh (2013), representante da medicina social latino-americana, a produção de doenças ocorre no plano coletivo e, portanto, não se pode desvincular o estudo do processo saúde-doença do contexto social em que está inserido. Nesse sentido, a fim de entender os processos pelos quais as relações sociais, a história e a cultura subordinam o biológico, é essencial investigar os sistemas estruturais de cada sociedade, cujas distintas formações sociais apresentam arranjos próprios e características particulares e, consequentemente, determinados perfis epidemiológicos.

Seguindo essa lógica, é possível correlacionar a alta prevalência dos transtornos mentais na atualidade com o aumento da exploração e opressão advindas do capitalismo, sistema que produz desigualdade e impede

Afiliação dos autores:

Universidade de Vassouras, Vassouras. RJ, Brasil

* Email de correspondência: : giovanna_innocencio@hotmail.com 
um objetivo maior de emancipação e qualidade de vida, e com o modo de produção neoliberal, cuja psicologia moral de produtividade e do ideal empresarial do sujeito produz e gerencia o sofrimento (SAFATLE; SILVA JUNIOR;DUNKER, 2020). Comoanalisado porBauman (1999), o desenvolvimento do capitalismo e a égide da ordem e do controle geraram a construção de um modo de vida atravessado por diferentes instituições sociais que regulam as formas de existência dos indivíduos. Para tanto, torna-se fundamental compreender como as condições impostas aos indivíduos interferem em seus meios de vivência e atentar para que não haja culpabilidade do sujeito quanto ao sofrimento que lhe é causado devido a falha do sistema em promover dignidade humana. De forma isolada, a área da saúde não consegue proporcionar vitalidade física e psíquica aos indivíduos - é necessário o empenho de parte significativa da sociedade para que seja assegurada a qualidade de vida ideal aos sujeitos.

A consideração dos processos históricos como um dos geradores das problemáticas existentes acerca da saúde coletiva, formalizando a existência da interface entre as ciências naturais e as ciências humanas, é de extrema importância para o estabelecimento adequado da saúde mental. À vista disso, partimos do pressuposto de que o reducionismo científico dificulta tal dialética, o que torna necessário discutir os possíveis fatores do adoecimento psíquico a partir da análise dos determinantes sociais e, assim, possibilitar uma apreensão sistemática do sofrimento mental.

\section{O processo saúde-doença e sua determinação sócio-histórica}

A medicina de Hipócrates, iniciada nos séculos V e IV a.C, valorizava a observação da natureza e explicava a origem das doenças a partir do desequilíbrio entre as forças naturais presentes no interior e no exterior dos indivíduos (GAMBA; TADINE, 2010; PUTTINI; PEREIRA JUNIOR; OLIVEIRA, 2010). Para o pai da Medicina moderna, o conceito de saúde era definido como a expressão de um equilíbrio completo do corpo humano. Com o avanço tecnológico da Medicina e, consequentemente, a evolução da complexidade das noções de causalidade, urge a necessidade de novas concepções teóricas acerca do tema.

Influenciada pelos paradigmas cartesianos, a ciência médica obteve considerável progresso a partir dos conhecimentos oriundos da Anatomia Humana. Nesse contexto, a partir do século XIX, o modelo biomédico apresentou-se na tentativa de compreender os fenômenos da saúde e da doença com bases nas ciências biológicas, adotando a ideia de que sempre existe um mecanismo etiopatogênico causador das enfermidades (GAMBA; TADINE, 2010; PUTTINI;
PEREIRA JUNIOR; OLIVEIRA, 2010). A partir dessa lógica unicausal, a saúde passou a ser definida como a ausência de doença, fazendo com que esse modelo se concretizasse de modo predominante na história da Medicina. A busca por novos paradigmas em saúde com base na crítica de que os fenômenos epidemiológicos tinham relação com a organização político-social da sociedade fez com que a Saúde Coletiva criasse um modelo contra-hegemônico (SOUSA; MACIEL; MEDEIROS, 2018; TESSER, 2006).

A criação da Organização Mundial da Saúde (OMS), no contexto do pós- $2^{\text {a }}$ Guerra Mundial, permitiu o surgimento do conceito de saúde como um "estado de completo bem-estar físico, mental e social e não a mera ausência de moléstia ou enfermidade" (OMS, 1946). Leavell e Clark (1976) apresentam o modelo da História Natural da Doença a partir da lógica multicausal com um esquema de tríade ecológica - agente, hospedeiro e meio ambiente. Emerge, então, um novo método de promoção da saúde, a partir da prevenção e controle das doenças. Apesar de reconhecer múltiplas determinações, esse modelo ainda recebeu forte influência do modelo biomédico, o que levou a um reducionismo da prática médica dentro da visão preventivista e ao vácuo da pergunta que surgia: comoutilizarúnica exclusivamente o modelo multicausal para o planejamento em saúde sem se erradicar a pobreza e dirimir a exclusão social, ou sem cair na ideologia da medicalização da sociedade (TESSER, 2006)?

Foi durante a década de 1960 que, em paralelo ao progresso tecnológico da ciência médica, a Medicina Social se manifesta contrapondo a hegemonia biomédica a partir das críticas apresentadas por diversos intelectuais latino-americanos (PUTTINI; PEREIRA JUNIOR; OLIVEIRA, 2010; VIAPIANA; GOMES; ALBUQUERQUE, 2018). A visão de que a epidemiologia clássica era insuficiente em abordar a saúde como um fenômeno que apresenta raízes na organização social dirigiu o olhar para a necessidade de um novo modelo explicativo a partir da vertente marxista, direcionando a uma práxis emancipadora. Isso, pois, o raciocínio epidemiológico tradicional do processo saúde-doença era baseado na ideia de que as enfermidades físicas e psíquicas existentes eram derivadas das respectivas características individuais, adotando perfis e padrões típicos de saúde (VIAPIANA; GOMES; ALBUQUERQUE, 2018).

Para a superação desse cenário, a criação de alternativas que abordassem as dimensões do indivíduo e do coletivo no processo saúde-doença viu-se necessária. No Brasil, durante a VII Conferência Nacional de Saúde, que ocorreu em 1986, foram discutidos os temas de reformulação do Sistema Único de Saúde (SUS), financiamento setorial e a saúde como direito. Foi adotado, então, o seguinte conceito de saúde: 
"Em seu sentido mais abrangente, a saúde é resultante das condições de alimentação, habitação, educação, renda, meio ambiente, trabalho, emprego, lazer, liberdade, acesso e posse da terra e acesso a serviços de saúde. É assim, antes de tudo, o resultado das formas de organização social da produção, as quais podem gerar grandes desigualdades nos níveis de vida" (BRASIL, 1986).

Portanto, parte-se do princípio de que o processo saúde-doença não é aleatório e arbitrariamente explicado apenas pela dimensão individual. A radicalidade de sua explicação se apresenta nas próprias relações sociais que se organizam de forma a permitir determinados modos de vida e, a depender de como esses diferentes modos de vida se articulam, são produzidos diferentes perfis epidemiológicos que se alteram no decorrer da história e nas diferentes sociedades e grupos sociais. Logo, a teoria da determinação social apresenta a urgência de entender o processo saúde-doença como um processo dinâmico, determinado pela sociedade e pela organização da produção social da vida em cada momento histórico (DIMENSTEIN et. al., 2017; NOGUEIRA, 2010). Apesar disso, é importante observar que esse processo também é sempre um processo biopsíquico - compreende-se que a sua determinação é social, mas que ela se concretiza nos próprios indivíduos ao se expressar no corpo e no psiquismo.

Isso posto, deve-se destacar o contraponto da teoria da determinação social à visão individualista do processo saúde-doença, ao mesmo tempo que considera a unidade biopsicossocial como sua base. Conclui-se que o social é, portanto, determinante do processo saúdedoença, uma vez que a existência do indivíduo depende das suas interrelações pessoais e para com a sociedade, onde a forma como esse processo se dá no indivíduo singular é dependente dos nexos entre a sua consciência produzidos a partir de sua ocupação no mundo.

\section{Saúde Mental e Sofrimento Psíquico}

Ao entender o processo saúde-doença como determinado socialmente, cabe retomar à ideia de Georges Canguilhem e Caponi (2011), que propõe a relação de limite entre o normal e o patológico. Para ele, o reducionismo positivista advém da necessidade de um desejo de intervenção que, em sua essência, se baseia em restaurar o organismo às normas estabelecidas pela cultura. Nesse sentido, esse limite é relativo a uma determinada sociedade e, portanto, depende do seu modo de organização e das normas subliminares que a influenciam (CANGUILHEM; CAPONI, 2011).

Nesse contexto, a saúde seria dada a partir da capacidade de se adaptar às exigências do meio e seguir novas normas de vida. De modo geral, segundo Canguilhem e Caponi (2011), o sofrimento psíquico é compreendido como uma expressão particular vivida pelos indivíduos como obstruções aos seus modos de viver a vida, tais quais são determinados pela necessidade de corresponder a certas exigências e critérios impostos pela sociedade.

Tais modos de vida são, portanto, dados pela inserção de cada indivíduo nas classes e grupos sociais em que cada um tem uma capacidade de se apropriar de objetivações humanas para seu desenvolvimento. O sofrimento psíquico é vivido como uma estagnação no desenvolvimento dessas pessoas, bem como uma iminência de decomposição, que concorre com processos que englobam relações de exploração, opressão e alienação.

De forma equivalente, Zygmunt Bauman lança um olhar crítico para as transformações sociais e econômicas trazidas pelo capitalismo globalizado (BAUMAN, 1999). Para ele, a quebra do paradigma capitalista industrial para o financeiro, mais maleável, levou o ser humano a tecer relações também maleáveis e líquidas. A liquefação das formas sociais de trabalho, família, engajamento político, amor, amizade e identidade, produz angústia, ansiedade e medo - temor do desemprego, da violência, da não-produtividade.

É fato que a vida produz uma série de processos que afetam a nossa existência, mas é qualitativamente diferente do sofrimento psíquico, que é produzido por uma privação imposta por determinadas relações sociais de produção que impedem o desenvolvimento adequado dos indivíduos.

\section{O capitalismo e a alta prevalência dos transtornos mentais na sociedade moderna}

Previamente à industrialização mecanizada e fabril, o homem já dominava formas de laboração praticadas na produção feudal, onde o processo produtivo estava sob o controle dos trabalhadores enquanto possuíam o poder de organização e comercialização (ROCHA; MARQUES 2018). A partir do surgimento de uma complexa divisão social do trabalho, foi introduzido o capital na tentativa de resolução das problemáticas de planejamento. Ao adentrar no processo de produção capitalista, as relações sociais começaram a se alterar à medida que o detentor do poder econômico e financeiro empreende na busca de acumulação e aumento contínuo de riqueza. Determina-se, então, uma trajetória de diferentes modelos de gestão do capital.

A sucessão dos regimes de acumulação capitalista contribuiu para um seguimento das dinâmicas dos processos de trabalho, das formas de regulação e do tipo de organização produtiva. O modelo fordista, prevalente a partir do início do século XX, era caracterizado pela produção e pelo consumo em massa, em que as principais formas de incapacidade no trabalho estavam 
relacionadas aos acidentes; nesse contexto, na sociedade, as doenças infectocontagiosas eram as mais prevalentes (MERLO; LAPIS 2007). A partir do surgimento de políticas públicas para o controle dessas epidemias como uma forma de responder às necessidades do próprio capital de manutenção da força de trabalho saudável, e também como uma resposta à organização dos trabalhadores e às suas reivindicações por melhores condições de vida e de trabalho, essas doenças passam a não ser tão expressivas.

$\mathrm{O}$ fordismo encontrou-se em profunda crise e em processo de dissolução e aniquilamento a partir da década de 1970, contexto de globalização em que surge o modelo de acumulação flexível (TEIXEIRA; SOUZA, 1985; GOERCK, 2009). À essa nova fase de acumulação do capital foram concebidas práticas de expropriação do trabalhador por meio da procura por crescimento do lucro e acumulação de riqueza. Baseado na flexibilidade do mercado e do processo de trabalho, esse modelo é favorável ao capitalista, uma vez que a desarticulação dos sindicatos, o aumento do desemprego estrutural, o aumento da competição e a grande quantidade de mão-de-obra excedente são fatores que deixam os trabalhadores com uma menor capacidade de reação. Essa situação acaba permitindo a flexibilização de acordos trabalhistas e ataque aos direitos sociais e do trabalho.

A partir da mudança no processo produtivo, as formas de adoecimento no trabalho também passaram a se transformar. Nesse momento, prevaleciam as doenças crônicas: lesões por esforço repetitivo (LER) e transtornos mentais pelo aumento da pressão imposta pela lógica do trabalho toyotista (MERLO; LAPIS, 2007; FRANCO; DRUCK; SELIGMANN-SILVA, 2010). Diante da impossibilidade de atender às exigências, cada vez maiores, dos processos de aceleração e pressão do capitalismo, ocorre a produção de um maior desgaste de disposição e energia biopsíquica dos indivíduos.

O neoliberalismo surge, aqui, como um ideário capaz de oxigenar as formas de acumulação do capitalismo. A hegemonia dos ideais neoliberais ocorre a partir dos anos 1970, com a globalização sendo entendida como um processo contemporâneo ancorado nas novas formas de tecnologia e rapidez de informações. Assiste-se a um cenário de concentração e internacionalização do capital, de reestruturação e racionalização empresarial, de ataques às conquistas dos trabalhadores e de mudanças importantes na estrutura da cadeia produtiva. Porém, como pontua Safatle, Júnior e Dunker (2020), além de atuar como um modelo socioeconômico, o neoliberalismo atua como psicologia moral do sofrimento, internalizando nos sujeitos práticas de gerenciamento do mal-estar, como individualização da culpa, repúdio ao fracasso depressivo, meritocracia, estados de anomia e mudanças permanentes e estruturação do sujeito empresarial produtivo.

Acompanhando a ascensão neoliberal, a reformulação da terceira edição do Manual Diagnóstico Estatístico de Transtornos Mentais (DSM-III), publicada em 1987, iniciou-se um processo de patologização e medicalização da vida, em que houve uma grande ampliação dos critérios diagnósticos, o que enquadrou muitas pessoas como portadoras de transtornos mentais (AMARANTE, 2015). Isso fez com que os indivíduos se transformassem em clientes da indústria farmacêutica que, consequentemente, está inserida na lógica capitalista. Cabe analisar que o próprio capitalismo precisa patologizar processos que antes não eram patologizados, uma vez que esse sistema necessita de pessoas cada vez mais resistentes às suas demandas. Como Karl Marx (2013, p. 164) afirma, "o processo capitalista de produção não é simplesmente produção de mercadorias. É processo que absorve trabalho não pago, que transforma os meios de produção em meios de extorsão de trabalho não pago".

Além da base econômica desse sistema funcionar a partir da exploração da força de trabalho, ela também funciona a partir da opressão de classe, raça e gênero. Ao se tratar da distribuição de renda entre os habitantes, o Brasil permanece o nono país mais desigual do mundo (ALMEIDA, 2020). Ao analisar a desigualdade de rendimentos, a população preta e parda permaneceu com metade do rendimento per capta observado para a população branca (MADEIRO, 2019). Ao se tratar de informalidade, a população preta ou parda está mais inserida em ocupações informais em todos os estados ao ser comparada à população branca (CAMPOS, 2020). Em relação aos homens, as mulheres estavam em maior proporção no trabalho auxiliar familiar, além de compor quase que integralmente o trabalho doméstico sem carteira (FILIZZOLA, 2020).

À vista disso, é importante destacar que, segundo a OMS, o Brasil é o país com maior prevalência de ansiedade no mundo e o quinto mais depressivo, sendo o segundo mais depressivo nas Américas (MORAES, 2020). Ao realizar um recorte, encontrase uma prevalência dos transtornos ansiosos de duas a três vezes maior nas mulheres em relação aos homens (ALMEIDA et al., 2019; ARAÚJO; PINHO; ALMEIDA, 2005), o que se pode relacionar com as formas de exploração capitalista e opressão de gênero que o próprio patriarcado impõe - duplas e triplas jornadas de trabalho e altos índices de violência doméstica, por exemplo. Sintomas de depressão foram vistos mais em mulheres negras $(52,8 \%)$ do que em mulheres brancas (42,3\%) (SMOLEN; ARAÚJO 2017), o que retrata a opressão racial existente no sistema, onde o racismo subalterniza e invisibiliza pessoas e povos não brancos intensificando a produção de sofrimento psíquico ao negar suas subjetividades. Os transtornos do humor em geral aparecem com expressiva presença 
nas notificações de faxineiras, operárias e professoras (ALMEIDA et al., 2019), configurando as baixas condições de trabalho como psicoestressores. Pessoas com baixa renda estão entre as maiores portadoras dos transtornos mentais (SILVA; SANTANA, 2012), sendo possível relacionar o sofrimento psíquico às péssimas condições de habitação, ao desemprego e à fome, bem como às poucas formas de acesso ao cuidado em saúde.

Enquanto menos de 1\% se beneficia das injustiças do sistema capitalista, os $99 \%$ restantes tentam acompanhar o ritmo para que consigam permanecer no mercado, estando sujeitos à exploração. Constatase, pois, que o sofrimento psíquico está em crescente aumento, não apenas por conta do aumento dos critérios diagnósticos, mas sim pois a vida continua a piorar. Quanto mais se intensifica os processos de exploração, mais a classe trabalhadora adoece. Isso nos permite analisar que as diferentes formas de adoecimento se dão a partir das diferenças entre os padrões de vida de cada grupo social, a depender do ritmo e da forma de execução do próprio trabalho, o que nos retoma à teoria de determinação social do processo saúde-doença.

\section{Atual cenário da Saúde Mental brasileira}

Historicamente, as áreas profissionais da Saúde Mental, principalmente a Psiquiatria, sempre estiveram ligadas aos interesses da classe dominante e, portanto, buscavam uma forma de tornar as pessoas mais "dóceis" e suscetíveis a exploração (FOUCAULT, 2014). Frantz Fanon (2008), psiquiatra e militante martinicano, enfatizava que a saúde mental deve ser contra os processos ideológicos dominantes e ser, primordialmente, um instrumento de desalienação.

A partir da redemocratização da sociedade brasileira durante a década de 1970, as políticas de Saúde Mental começaram a ser revistas no país, principalmente pela influência do processo da Reforma Psiquiátrica que ocorria no mundo (AMARANTE, 2007). A experiência basagliana $^{1}$ colocou a enfermidade entre parênteses, e passou a introduzir o sujeito e seu contexto de vida como ponto central. Tais perspectivas convergem e se materializam no próprio conceito ampliado de saúde, reforçado pela Constituição Federal de 1988 e

perpetuado pelo Sistema Único de Saúde (SUS), em que os determinantes sociais do processo saúde-doença passam a ganhar destaque (COMISSÃO NACIONAL SOBRE DETERMINANTES SOCIAIS DA SAÚDE, 2008).

Emerge, então, a atenção comunitária, apresentando a Rede de Atenção Psicossocial (RAPS) inserida no Sistema Único de Saúde (SUS), que tem como base teórica o conceito de territorialidade (AMARANTE, 2007). Nesse sentido, os cuidados em saúde mental passaram a ser organizados considerando a perspectiva de território em rede, com os Centros de Atenção Psicossocial (CAPS) se mostrando à frente desse novo modelo. Tais centros são considerados excepcionais na organização da rede de assistência em saúde e na reinserção dos indivíduos em sofrimento psíquico na sociedade.

No entanto, essas políticas públicas que vinham propondo formas de cuidado e estratégias de enfrentamento individuais e coletivas ao seu processo de sofrimento vêm sofrendo um sucateamento ao longo dos últimos anos (CRUZ; GONÇALVES; DELGADO, 2020). Por trás disso, é possível analisar que há o objetivo de financiar os grupos que se beneficiam dessa política. Ao final de 2020, mudanças na Política Nacional de Saúde Mental e na Política Nacional de Álcool e outras Drogas foram apresentadas por integrantes do Governo Federal e, com o apoio do Ministério da Saúde, os representantes defenderam medidas drásticas, como a revogação de mais de cem atos normativos que regulam a Saúde Mental desde a década de 1990 em consonância com a Reforma Psiquiátrica (AMADO, 2020). É importante destacar que todas essas propostas convergem com um documento orientativo da Associação Brasileira de Psiquiatria e outras entidades médicas.

A centralidade biomédica sobre os demais setores científicos e profissionais é um exemplo de políticas antiquadas que estão sendo defendidas atualmente. Enquanto os brasileiros mais necessitam e demandam do SUS, em meio a uma das piores crises sanitárias da história - a pandemia do novo Coronavírus - e ao incremento da prevalência dos transtornos mentais no país, o Governo Federal organiza um desmonte dos direitos da população.

Hoje, o Brasil enfrenta a urgente necessidade de fortalecimento das políticas públicas assistenciais, e não a descontinuação desses serviços. Tudo isso é preocupante tanto do ponto de vista do sofrimento individual, uma vez que as pessoas se encontram cada vez mais sem perspectivas de vida e de cuidado em saúde, quanto do ponto de vista coletivo, em que há um desânimo ao engajamento em projetos de resistência e transformação do próprio sistema que produz esse adoecimento.

Para Foucault (2006), o despertar ético a partir do cuidado de si, para consigo e para com os outros, resulta em um sujeito ético-político de postura ativa capaz de resistir ao biopoder em prol de uma coletividade. Nesse sentido, Franco Basaglia (2005) enfatizou que os técnicos da saúde mental devem estar aliados aos projetos de transformação da classe trabalhadora, pois é nessa aliança que nossas ações se potencializam, uma vez que toda dedicação que a gente dê ainda vai ser insuficiente para transformar as condições que 
produziram seu adoecimento.

${ }^{1}$ Franco Basaglia, psiquiatra italiano, é referência mundial na busca pela transformação do modelo de assistência à saúde mental. Sua incansável luta contra a violência das instituições totais e, em particular, do manicômio, iniciou nos anos em que trabalhou nos manicômios de Gorizia e Trieste. Basaglia visava a destruição de todo o sistema manicomial, e não apenas a sua reforma, sendo considerado, portanto, um revolucionário (SERAPIONI, 2019).

\section{Considerações finais}

A docilização dos corpos vai contra os princípios de autonomia, que filosoficamente se entrelaça com liberdade, uma vez que, por meio da disciplina, os mecanismos tornam o indivíduo mais obediente e útil. O discurso psiquiátrico hegemônico situa a problemática do sofrimento psíquico apenas nos limites do indivíduo, desconectando-o do seu meio sociopolítico, o que reforça a ideia do corpo doente que deve ser objeto de controle e intervenção.

Frente à observação da epidemiologia dos transtornos mentais na sociedade brasileira, a partir da visão da teoria da determinação social do processo saúdedoença, percebe-se como o sistema socioeconômico vigente impõe enorme influência no sofrimento pessoal e coletivo, dada a crescente desigualdade de gênero, raça e classe produzida pela exploração. O modelo de produção capitalista, fundado na alienação do trabalho, empobrece a subjetividade e condena o sujeito a uma vida alienada e sem significado.

É importante, então, que se desnaturalize o cuidado do corpo como objeto privado das ciências da saúde, especialmente da Medicina. Entender o social como determinante do adoecimento psíquico é essencial para que se crie políticas efetivas de cuidado em saúde. Ao mesmo tempo que isso ocorre, muitos profissionais vivem essas contradições no cotidiano e percebem sua impotência na prática, observando o quão necessário é abordar outras formas de resistência.

A piora das condições de vida não nos apresenta outra alternativa senão nos organizar contra essas políticas e, principalmente, contra o capitalismo. $\mathrm{O}$ desenvolvimento da utopia ocorrerá, portanto, a partir da luta contra a opressão, em que o desejo consciente de liberdade e emancipação, bem como a busca pela saúde física e, sobretudo, mental, abrirá o caminho em direção à sua realização.

\section{Referências}

ALMEIDA, C. Brasil é nono país mais desigual do mundo, diz IBGE. O Globo, Rio de Janeiro, nov. 2020. Disponível em: https://oglobo.globo.com/ economia/brasil-nono-pais-mais-desigual-do-mundo-diz-ibge-24742041. Acesso em: 20 mar. 2021

ALMEIDA, M. M. C. et al. Boletim Epidemiológico dos Transtornos Mentais relacionados ao Trabalho. Instituto de Saúde Coletiva, Bahia, abr. 2019. Disponível em: <https://www.analisepoliticaemsaude.org/oaps/documentos/ noticias/ccvisat-bol-transtmentaisfinal-260419/>. Acesso em: 20 mar. 2021.
AMADO, G. Governo Bolsonaro revogará portarias e encerrará programas de saúde mental no SUS. Revista Época, Rio de Janeiro, 2020. Disponível em: <https://oglobo.globo.com/epoca/guilherme-amado/governo-bolsonarorevogara-portarias-encerrara-programas-de-saude-mental-no-sus-124782439>. Acesso em: 20 mar. 2021.

AMARANTE, P. Medicalização em psiquiatria. $1^{\text {a }}$ ed., Rio de Janeiro: Editora Fiocruz, 2015.

AMARANTE, P. Saúde mental e atenção psicossocial. $1^{\text {a }}$ ed., Rio de Janeiro: Editora Fiocruz, 2007.

ARAÚJO, T. M.; PINHO, O. S.; ALMEIDA, M. M. G. Prevalência de transtornos mentais comuns em mulheres e sua relação com as características sociodemográficas e o trabalho doméstico. Rev. Bras. Saúde Matern. Infant., Recife, v. 5, n. 3, p. 337-348, jul./set. 2005. Disponível em: https:// www.scielo.br/j/rbsmi/a/6vSkSdfMXfDsWj9q9RFymcd/?lang=pt. Acesso em: 23 mar. 2021.

BAUMAN, Z. Globalização: as conseqüências humanas. Rio de Janeiro: Jorge Zahar, 1999.

BASAGLiA, F. Escritos Selecionados em Saúde Mental e Reforma Psiquiátrica. $1^{\mathrm{a}}$ ed., Rio de Janeiro: Garamond, 2005.

BRASIL. Ministério da Saúde. Relatório final da VIII Conferência Nacional de Saúde, 1986. Disponível em: https://bvsms.saude.gov.br/bvs/ publicacoes $/ 8$ _conferencia_nacional_saude_relatorio_final.pdf. Acesso em: 23 mar. 2021.

BREILH, J. La determinación social de la salud como herramienta hacia una nueva salud pública (salud colectiva). Revista Facultad Nacional de Salud Pública, Antioquia, n. 31, supl. 1, p. 13-27, 2013. Disponível em: http://www.scielo.org.co/scielo.php?script=sci arttext\&pid=S0120 386X2013000400002. Acesso em: 22 mar. 2021.

CAMPOS, A.C. IBGE: informalidade atinge 41,6\% dos trabalhadores no país em 2019. Agência Brasil, Rio de Janeiro, nov. 2020. Disponível em: $\quad<$ https://www.cut.org.br/noticias/informalidade-atinge-47-4-dostrabalhadores-negros-do-brasil-diz-ibge-766e>. Acesso em: 20 mar. 2021.

CANGUILHEM, G.O; CAPONI, S. O normal e o patológico. $7^{\mathrm{a}}$ ed., São Paulo: Editora Manole, 2011.

COMISSÃO NACIONAL SOBRE DETERMINANTES SOCIAIS DA SAÚDE. As causas sociais das iniquidades em saúde no Brasil. Relatório final da comissão nacional sobre determinantes sociais da saúde (CNDSS), Rio de Janeiro: Editora Fiocruz, 2008. Disponível em: https:/bvsms.saude. gov.br/bvs/publicacoes/causas_sociais_iniquidades.pdf. Acesso em: 23 mar. 2021.

CRUZ, N. F. O.; GONÇALVES, R. W.; DELGADO, P. G. G. Retrocesso da reforma psiquiátrica: o desmonte da política nacional de saúde mental brasileira de 2016 a 2019. Rev. Trabalho, Educação e Saúde, Rio de Janeiro, v. 18, n. 3, 2020. Disponível em: https://www.scielo.br/j/tes/a/j6rLV ysBzMQYyFxZ6hgQqBH/?lang=pt. Acesso em: 24 mar. 2021.

DIMENSTEIN, M. et al. Determinação social da saúde mental: contribuições da psicologia no cuidado territorial. Arquivos Brasileiros de Psicologia, Rio de Janeiro, v. 69, n. 2, p. 72-87, 2017. Disponível em: http://pepsic.bvsalud. org/scielo.php?script $=$ sci arttext\&pid $=$ S1809-52672017000200006. Acesso em: 21 mar. 2021

FANON, F. Pele negra, máscaras brancas. $1^{\mathrm{a}}$ ed., Bahia: Editora EDUFBA, 2008.

FILIZZOLA, L. O crescimento da informalidade no país: quem são os mais atingidos pela precarização do trabalho? Observatório de Desigualdades, Minas Gerais, nov. 2020. Disponível em: http://observatoriodesigualdades. fjp.mg.gov.br/?p=1403. Acesso em: 20 mar. 2021

FOUCAULT, Michel. A Hermenêutica do Sujeito. $2^{\text {a }}$ ed. São Paulo: Martins Fontes, 2006.

FOUCAULT, M. Vigiar e punir. 42ª ed., Petrópolis: Editora Vozes, 2014.

FRANCO, T.; DRUCK, G; SELIGMANN-SILVA, E. As novas relações de trabalho, o desgaste mental do trabalhador e os transtornos mentais no trabalho precarizado. Rev. Bras. Saúde Ocup., São Paulo, v.35, n.122, p. 229-248, 2010. Disponível em: https://www.scielo.br/j/rbso/a/TsQSX3zBC 8wDt99FryT9nnj/?lang=pt. Acesso em: 20 mar. 2021. 
GAMBA, M.A.; TADINE, A.C.O. Processo Saúde-Doença. Mimeografado, 2010 .

GOERCK, C. Capitalismo e as transformações no Processo de Trabalho. Rev. Capital Científico, Guarapuava, v. 7, n.1, p. 11-20, 2009. Disponível em: https://revistas.unicentro.br/index.php/capitalcientifico/article/view/731. Acesso em: 20 mar. 2021.

HIANY, N. et al. Perfil Epidemiológico dos Transtornos Mentais na População Adulta no Brasil: uma revisão integrativa. Rev. Enfermagem Atual Inderme, Rio de Janeiro, v. 86, n. 24, 2020. Disponível em: https:// revistaenfermagematual.com.br/index.php/revista/article/view/676. Acesso em: 24 mar. 2021

LEAVELL, H.; CLARK, E.G. Medicina Preventiva. São Paulo: McGrawHill, 1976.

MADEIRO, C. Negros são 75\% entre os mais pobres; brancos, $70 \%$ entre os mais ricos. Revista UOL, Fortaleza, nov. 2019. Disponível em: $\quad$ https://noticias.uol.com.br/cotidiano/ultimas-noticias/2019/11/13/ percentual-de-negros-entre-10-mais-pobre-e-triplo-do-que-entre-mais-ricos. htm?cmpid=copiaecola. Acesso em: 20 mar. 2021.

MARX, Karl. O Capital: Crítica da Economia política: Livro I. São Paulo: Boitempo, 2013.

MERLO, A. R. C.; LAPIS, N. L. A saúde e os processos de trabalho no capitalismo: reflexões na interface da psicodinâmica do trabalho e da sociologia do trabalho. Rev. Psicol. Soc., Porto Alegre, v. 19, n.1, p. 61-68, 2007. Disponível em: https://www.scielo.br/j/psoc/a/d4BywgBQn9QkpbLQ sXVGPcP/?lang=pt. Acesso em: 22 mar. 2021.

MORAES, A. L. Brasil é país mais deprimido e ansioso da América Latina. Revista Veja Saúde, São Paulo, nov. 2020. Disponível em: https://saude. abril.com.br/mente-saudavel/brasil-e-o-pais-mais-deprimido-e-ansioso-daamerica-latina. Acesso em: 20 mar. 2021.

NOGUEIRA, R.P. Determinação social da saúde e reforma sanitária. CEBES, Rio de Janeiro, 2010.

OMS, Organização Mundial da Saúde. Constituição da Organização Mundial da Saúde (OMS/WHO), Nova York, 1946.

PUTTINI, R. F.; PEREIRA JUNIOR, A.; OLIVEIRA, L. R. Modelos explicativos em saúde coletiva: abordagem biopsicossocial e autoorganização. Rev. de Saúde Coletiva, Rio de Janeiro, v. 20, n. 2, p. 753-767, 2010. Disponível em: https://www.scielo.br/j/physis/a/fGQr7m9LdpmHqh4 fwmhCrpc/?lang=pt. Acesso em: 20 mar. 2021.

ROCHA, M. A. R. S.; MARQUES, D. P. Os modelos de produção capitalista e a exploração do trabalhador: da manufatura ao precariado. VI Seminário CETROS, UECE, Itaperi, 2018. Disponível em: http://www.uece.br/ eventos/seminariocetros/anais/trabalhos_completos/425-39386-11072018143651.pdf. Acesso em: 22 mar. 2021.

SAFATLE, V; SILVA JÚNIOR, N.; DUNKER, C. Neoliberalismo como gestão do sofrimento psíquico. Belo Horizonte: Autêntica Editora, 2020.

SANTOS, É. G.; SIQUEIRA, M. M. Prevalência dos transtornos mentais na população adulta brasileira: uma revisão sistemática de 1997 a 2009. J Bras Psiquiatr., Rio de Janeiro, v. 59, n. 3, p. 238-246, 2010. Disponível em: https://www.scielo.br/j/jbpsiq/a/FNQ5qZjtSdwznsjZzHTH7jS/?lang=pt . Acesso em: 23 mar. 2021.

SERAPIONE, M. Franco Basaglia: biografia de um revolucionário. Rev. História Ciências Saúde - Manguinhos, Rio de Janeiro, v. 26, n. 4, p. 11691187, 2019. Disponível em: https://www.scielo.br/j/hcsm/a/xyFt7t59w8czH WXY3TSgLVC/?lang=pt. Acesso em: 24 mar. 2021.

SILVA, D. F; SANTANA, P. R. Transtornos mentais e pobreza no Brasil: uma revisão sistemática. Rev. Tempus Actas de Saúde Coletiva, Brasília, v. 6, n. 4, 175-185, 2012. Disponível em: https://www.tempusactas.unb.br/ index.php/tempus/article/view/1214. Acesso em: 22 mar. 2021.

SMOLEN, J.R; ARAÚJO, E.M. Raça/cor da pele e transtornos mentais no Brasil: uma revisão sistemática. Rev. Ciência \& Saúde Coletiva, Rio de Janeiro, v. 22, n. 12, p. 4021-4030, 2017. Disponível em: https://www.scielo. $\mathrm{br} / \mathrm{j} / \mathrm{csc} / \mathrm{a} / \mathrm{RJbPdTCPbgSFcMpMYjbh8Fv/?lang=pt.} \mathrm{Acesso} \mathrm{em:} 22$ mar. 2021

SOUSA, P. F.; MACIEL, S. C.; MEDEIROS, K. T. Paradigma biomédico $\mathrm{X}$ psicossocial: onde são ancoradas as representações sociais acerca do sofrimento psíquico? Trends Psychol., Ribeirão Preto, v. 26, n. 2, p. 883895, 2018. Disponível em: https://www.scielo.br/j/tpsy/a/KpjrW4hrdsLPCQ Z5sJjrbYs/?lang=pt. Acesso em: 20 mar. 2021.

TEIXEIRA, D. L. P.; SOUZA, M. C. A. F. Organização do processo de trabalho na evolução do capitalismo. Rev. Adm. Empr., Rio de Janeiro, v. 25, n. 4, p. 65-72, 1985. Disponível em: https://www.scielo.br/j/rae/a/6JVy5 BfzcBL9C64MW5NfQ8G/?lang=pt. Acesso em: 22 mar. 2021.

TESSER, C. D. Medicalização social (II): limites biomédicos e propostas para a clínica na atenção básica. Interface Saúde Educação, São Paulo, v. 10, n. 20, p. 347-62, 2006. Disponível em: https://www.scielo.br/j/icse/a/W4 TYpLSPjNRJdfnQVzVhQFF/?lang=pt. Acesso em: 20 mar. 2021.

VIAPIANA, V. N.; GOMES, R. M.; ALBUQUERQUE, G. S. C. Adoecimento psíquico na sociedade contemporânea: notas conceituais da teoria da determinação social do processo saúde doença. Rev. Saúde Debate, Rio de Janeiro, v. 42, n. 4, p. 175-186, 2018. Disponível em: https://www.scielo.br/j/ sdeb/a/Y36fDqvZL5Js4nnWpXrYpBb/?lang=pt. Acesso em: 20 mar. 2021. 